\title{
Content validity of a sleep numerical rating scale and a sleep diary in adults and adolescents with moderate-to-severe atopic dermatitis
}

\author{
Carla Dias-Barbosa ${ }^{1}$, Rodolfo Matos ${ }^{2^{*}}$ (D, Margaret Vernon ${ }^{2}$, Colleen E. Carney ${ }^{3}$, Andrew Krystal ${ }^{4}$ and Jorge Puelles ${ }^{5}$
}

\begin{abstract}
Background: The intense itching associated with atopic dermatitis (AD) often causes patients to experience severe sleep disturbance. Here, we describe the results of a two-phase concept elicitation and cognitive interview study to establish the content validity of a sleep disturbance numerical rating scale (SD NRS) and a Consensus Sleep Diary adapted for adults and adolescents with moderate-to-severe AD (CSD-AD○).

Results: In phase I, a concept elicitation conducted in 20 adults and 10 adolescents with moderate-to-severe AD revealed that the following sleep-related issues were important and relevant: nighttime awakening (87\%), trouble falling asleep (73\%), feeling unrested (53\%), daytime fatigue or sleepiness (53\%), and feeling as if they did not get enough sleep (33\%). The frequency and extent of sleep disturbance varied substantially from day to day due to varying degrees of itching and flares, medication use, and changes in the weather. All participants understood the SD NRS question, with most finding it easy or very easy to understand (100\% of adults and $90 \%$ of adolescents) and most understanding the anchors as intended (95\% of adults, and 100\% of adolescents). Most participants (94\% of adults, and $90 \%$ of adolescents) indicated that they would consider a one- or two-point change meaningful on the SD NRS. The CSD-AD@ was revised based on participant feedback, and tested during phase II in a convenience sample of six adults and four adolescents from phase I. The changes made to the CSD-AD@ were confirmed to be relevant and understandable. All patients were able to provide an answer to each item in the CSD-AD®, and most were able to estimate the duration of nighttime awakenings, daytime naps, and dozing.
\end{abstract}

Conclusions: The study supported the content validity of the SD NRS and CSD-AD@ in adults and adolescents with moderate-to-severe AD. It also emphasized the importance of using these instruments daily when assessing the benefit of a new treatment on sleep quality in this population.

Keywords: Atopic dermatitis, Sleep, Patient-reported outcomes, Content validity

\section{Background}

Atopic dermatitis (AD) is a common relapsing inflammatory skin condition characterized by pruritus, erythema, and lichenified skin lesions [1]. AD usually appears in childhood and, in most cases, improves with age. However, in about one in five patients, it persists

\footnotetext{
* Correspondence: rodolfo.matos@evidera.com

Evidera, 7101 Wisconsin Avenue, Suite 1400, Bethesda, MA 20814, USA

Full list of author information is available at the end of the article
}

into adulthood [1]. AD is thought to be caused by skin barrier dysfunctions that lead to increased immune reactions and inflammation $[1,2]$.

The intense itching associated with $\mathrm{AD}$ often causes patients to experience severe sleep disturbance, leading to daytime sleepiness and sleep-related impairment $[1$, 3-5]. Compared to patients with AD who do not report sleep disturbance, those who report sleep disturbance more often miss work, have doctor visits, and experience 
difficulties performing daily tasks [6, 7]. Sleep disturbance is reported by $33 \%$ to $87 \%$ of patients with $\mathrm{AD}$ [3], and as few as one in five patients report having good or very good sleep quality [5].

Although sleep disturbance is a significant problem for patients with $\mathrm{AD}$, clinical trials examining $\mathrm{AD}$ treatments have usually focused on physician-assessed outcomes [3, 8]. Reliable tools for assessing sleep disturbance from the patient perspective are lacking [3]. Simple concepts such as itch or pain are often assessed using single-item questionnaires, whereas complex concepts such as sleep disturbance require a more detailed approach to capture the multidimensionality and daily variability of the concept. Thus, a single-item scale, such as a single NRS administered daily, is not sufficient to adequately capture the multidimensionality of the sleep disturbance concept. However, combined with a multiitem diary, it could be an appropriate approach for assessing the benefit of an intervention.

Actigraphy and polysomnography have been used to quantitatively measure objective aspects of sleep $[9,10]$, but they do not capture how individuals feel or function in daily life, cannot examine the effect of an intervention from the patient perspective, often do not correlate well with subjective assessments of sleep using diaries, and, in the case of actigraphy, have limited usefulness for assessing sleep onset latency and duration of awakenings $[8,11]$. Several patient-reported outcomes (PROs) for assessing sleep are available. These include the Pittsburgh Sleep Quality Index for adults [3] and the PROMIS Sleep Disturbance and sleep-related impairment item banks [5]. Several other instruments are available for assessing sleep quality in children, adolescents, and adults $[12,13]$. However, these instruments were not developed in consultation with $\mathrm{AD}$ patients, and, therefore, cannot be assumed to be fit-for-purpose or adequate for them.

According to best practices for clinical research and regulatory requirements, PROs should be consistent with the patients' experiences and measure concepts that are clinically relevant and important to them to be considered to have content validity [14-16]. This involves first establishing the relevance of the specific concepts measured in the PRO and then testing the PRO in the intended population to ensure that the instructions are clear and the content of each question, response scale, and recall period are correctly interpreted and understood $[14,16,17]$. In the current study, qualitative data were collected to document the importance and relevance of sleep disturbance in adolescents and adults with moderate-to-severe $\mathrm{AD}$ and to establish the content validity of a one-item sleep disturbance numerical rating scale (SD NRS) and a version of the Consensus Sleep Diary [11] adapted to patients with AD (CSD-ADఠ). To aid the interpretation of the SD NRS data in clinical trials, information on what patients would consider a meaningful change was also collected.

\section{Methods \\ Participants}

Participants were identified and recruited across six clinical sites in the US (California, Florida, New York, and Texas). Participants had to be aged $\geq 12$ years; have a clinical diagnosis of moderate-to-severe $\mathrm{AD}$, as defined by an Eczema Area and Severity Index (EASI) $\geq 12$ within 2 weeks of study enrollment [11]; and have a score $\geq 4$ on the SCORing Atopic Dermatitis (SCORAD) sleep loss visual analog scale (VAS) [18] within 2 weeks of study enrollment. Participants also had to be able to read and understand English sufficiently to participate in a telephone interview and complete the assessments. Participants were excluded if they had a significant speech impairment, cognitive impairment, hearing difficulty, visual impairment, or severe psychopathology in the opinion of the site's clinical staff. Efforts were made to recruit a diverse sample of patients that included adolescents (12-17 years), young adults (18-30 years), middle-aged adults (31-45 years), and mature adults ( $\geq 46$ years).

\section{Phase I}

Phase I consisted of a hybrid concept elicitation and cognitive debriefing interview phase to provide evidence to support the content validity of the SD NRS and CSDADC. Phase I included 20 adults and 10 adolescents with moderate-to-severe $\mathrm{AD}$, moderate-to-severe pruritus, and sleep disturbance. Participants completed the original versions of the CSD-AD॰ and SD NRS and were interviewed about the instruments during one-onone, semi-structured telephone sessions.

Evidence on content validity was gathered through concept elicitation exploring patient experiences, with the objective of determining whether the SD NRS measured a concept of relevance and importance to patients with AD. Concept elicitation was followed by cognitive debriefing to assess whether the participants fully understood the SD NRS and to determine how easily they could complete the SD NRS. Specific probes were used to discuss information not spontaneously reported by participants (e.g. frequency, severity, and duration of sleep disturbance). If a participant did not spontaneously report a concept covered by the CSD-AD, they were probed to determine its relevance. Participants' perspectives of meaningful change thresholds for the SD NRS and "no or minimal" sleep disturbance were also elicited by asking participants what change from the current day's score they would consider to be the smallest improvement that they would be satisfied with and what 
number on the scale they would consider a meaningful improvement. Participants were also asked what score on the SD NRS they would consider as indicating no or minimal sleep disturbance. The information collected was used to assess and refine the content of the CSD$\mathrm{AD \odot}$. Based on participant feedback from phase I, the CSD-AD@ was modified and tested in phase II.

\section{Phase II}

During phase II, a convenience sample of 10 participants from phase I completed the revised version of the CSD$\mathrm{AD} \odot$. These participants were interviewed about the instruments during one-on-one, semi-structured telephone sessions to examine the content validity of the CSD$\mathrm{AD} \odot$ and ensure that any revisions were relevant, comprehensive, and understandable.

\section{SD NRS}

The SD NRS was a single-item, self-reported 11-point scale ranging from zero to 10 for reporting the degree of sleep loss related to AD.

\section{CSD-ADC}

The CSD-AD@ was adapted from the Consensus Sleep Diary, a standardized, prospective tool for tracking nightly subjective sleep that was developed by experts and refined with patient input [11]. The Consensus Sleep Diary contains core items for assessing insomnia that are not modifiable, but it allows for a variety of optional items to be included. For the CSD-AD $\odot$, items that related to $\mathrm{AD}$ specifically were added, and some items were modified to be relevant for this population and to capture sleep disturbance attributed to AD symptoms. The original version of the CSD-ADC used in phase I consisted of nine items to be completed in the morning assessing concepts related to time until sleep onset, nighttime awakenings, total sleep time, and sleep quality (items 1-9), and two items to be completed in the evening assessing daytime naps and dozing (items 10a and 10b) (Table 1). For phase II, the CSD-AD® was revised based on participant feedback from phase I. The revised version of the CSD-AD@ used in phase II included 11 items to be completed in the morning that assessed concepts related to disrupted nighttime sleep and sleep quality (morning items 1-11) and four items to be completed in the evening that assessed daytime naps and dozing (evening items 1-4). No further changes were made following phase II.

\section{Clinician-reported outcomes}

The EASI is a clinician-reported scale designed to measure the severity and extent of AD [19]. The EASI is a composite score based on the total area affected and intensity of redness, thickness, scratching, and latensification on the head/neck, trunk, upper limbs, and lower limbs. The score ranges from 0 to 72 , with a higher score indicating more severe $\mathrm{AD}$.

SCORAD is a hybrid clinician- and self-reported tool that includes the extent, intensity, and symptoms of $\mathrm{AD}$ [18]. The SCORAD total score ranges from 0 to 103 , with a higher score indicating more severe AD. Included in SCORAD are VASs in which sleeplessness and pruritus are scored from 0 for "none" to 10 for "worst possible."

\section{Interviews}

The interviews followed the methodology of the US Food and Drug Administration and ISPOR for developing PRO instruments $[15,16,20]$. All interviews were conducted in US English by trained qualitative researchers. Clinical site investigators were responsible for ensuring that all participants fully understood the nature and purpose of the interview. Potential participants received a consent form describing the details of the study, which they reviewed with the site's clinical staff, and were given the opportunity to ask questions about the study.

After providing informed consent, each participant was sent an interview pack that contained the CSD-AD $\odot$ and SD NRS in a sealed envelope. Participants were asked not to open the envelopes until the time of the interview session. They were asked to return the completed questionnaires after completion of the interview. Demographic and clinical data, EASI scores, and the SCORAD were collected from eligible, consenting participants by the site's clinical staff.

Experienced and trained staff conducted interviews by telephone using semi-structured interview guides. Interviewers were trained in study-specific objectives and the sponsor's adverse event reporting requirements.

The discussion guides began with open-ended questions that were followed by semi-structured interviews. The discussion guides included probes for interviewers to obtain detailed information on specific issues not spontaneously reported by the participants. For the concept elicitation portion, participants were asked openended questions about their experiences with $\mathrm{AD}$ and sleep disturbance. The patients' perspectives on meaningful change in the SD NRS were probed, including the smallest improvement with which the participants would be satisfied or content, the level of improvement that they would consider meaningful, and what they would consider a "no or minimal" sleep disturbance. For the cognitive debriefing portion, participants were asked questions about the comprehension, relevance, and acceptability of the SD NRS and CSD-AD@.

All identifying information was removed from the transcripts to maintain the confidentiality of all 
Table 1 Items Included in the Original and Revised Versions of the CSD-AD॰ and SD NRS

\begin{tabular}{|c|c|c|}
\hline Instrument & Original Version (used in phase II) & Revised/Final Version \\
\hline \multirow[t]{4}{*}{$\overline{C S D-A D \odot}$} & $\begin{array}{l}\text { Item 1: What time did you get into } \\
\text { bed? }\end{array}$ & Morning item 1: What time did you get into bed? \\
\hline & $\begin{array}{l}\text { Item 2: What time did you try to go } \\
\text { to sleep? }\end{array}$ & Morning item 2: What time did you try to go to sleep? \\
\hline & $\begin{array}{l}\text { Item 3: How long did it take you to } \\
\text { fall asleep? }\end{array}$ & Morning item 3: How long did it take you to fall asleep? \\
\hline & $\begin{array}{l}\text { Item 4a: How many times did you } \\
\text { wake up, not counting your final } \\
\text { awakening? }\end{array}$ & $\begin{array}{l}\text { Morning item 4: How many times did you wake up due } \\
\text { to the symptoms of atopic dermatitis (for example } \\
\text { itching, burning), not counting the final time you woke } \\
\text { up for the day? }\end{array}$ \\
\hline
\end{tabular}

Item 5b: In total, how long did these itch-related awakenings last?

Item 4b: How many times did you wake up due to itching, not counting your final awakening?

Item 5a: In total, how long did these awakenings last?

Item 6: What time was your final awakening?

(No item)

Item 7: How would you rate the quality of your sleep?

Item 8: How rested or refreshed did you feel when you woke up for the day?

Item 9: Did you take any sleep (Deleted) medication last night?

Item 10a: How many times did you nap or doze?

Item 10b: In total, how long did you nap or doze?

SD NRS In instructions, atopic dermatitis abbreviated "AD"

Anchor for the maximum score (10) defined as "I cannot sleep at all"
Morning item 5: In total, how long did the awakenings related to the symptoms of atopic dermatitis (for example itching, burning) last?

Morning item 6: How many times did you wake up, for other things (for example to drink water, to go to the bathroom), not counting the final time you woke up for the day?

Morning item 7: In total, how long did these awakenings to the bathroom) last?

Morning item 8: What time did you wake up for the day?

New morning item 9: What time did you get out of bed for the day?

Morning item 10: How would you rate the quality of your sleep?

Morning item 11: How rested or refreshed did you feel when you woke up for the day?

Evening item 1: How many times did you nap?

Evening item 2: In total, how long did you nap?

Evening item 3: How many times did you doze off?

Evening item 4: In total, how long did you doze off?

In instructions, "atopic dermatitis" spelled out

Anchor for the maximum score (10) defined as "I did not sleep at all" related to other things (for example to drink water, to go

\section{Change Made}

No change

No change

No change

Added "due to the symptoms of atopic dermatitis (for example itching, burning)"

Replaced "final awakening" by "final

time you woke up for the day"

Examples provided in the

instructions adjusted accordingly

Added "awakenings related to the symptoms of atopic dermatitis (for example itching, burning)"

Added "for other things (for example to drink water, to go to the bathroom)"

Replaced "final by "final time you woke up for the day"

Added "for other things (for example to drink water, to go to the bathroom)"

Replaced "final awakening" by "time did you wake up for the day"

Insertion of item 7 from the Consensus Sleep Diary [11] to be able to derive sleep metrics

No change

No change

Removed because sleep medications are usually not allowed in clinical trials of atopic dermatitis

No change; broken down into separate questions

Changed from "AD" to "atopic dermatitis"

Changed from "cannot" to "did not"

Abbreviations: $C S D-A D \odot$ Consensus Sleep Diary, atopic dermatitis version, SD NRS sleep disturbance numerical rating scale

protected health information. Interviews lasted approximately $90 \mathrm{~min}$ and were audio recorded.

\section{Data management and quality control}

Audio-recorded data collected during the interviews were transcribed by third-party professional transcription services. Audio files from the interviews were reviewed by the scientific staff for quality assurance purposes to remove public health information and correct obvious transcription errors. Quantitative sociodemographic and clinical data were transmitted using a secure file transfer portal directly into the electronic system database. An electronic image of the case report form was then entered into the database and reviewed by project scientific staff. Data discrepancies were identified and resolved.

The scientific staff was responsible for the overall direction and supervision of the data collection, as well as 
for monitoring the study progress and quality control of data. All work was subject to quality control, as well as documentation procedures to ensure that the data were accurate, and the analyses could be reproduced.

\section{Data analysis}

Sociodemographic and clinical characteristics collected in phase I were characterized using descriptive statistics for the entire participant sample. Quantitative analyses were performed using SAS version 9.4 (SAS Institute, Cary, NC, USA) [21].

Qualitative data collected in transcripts were analyzed using a content analysis approach. The coding process was driven by the objectives of the study and consisted of tagging codes to segments of textual data to facilitate the comprehension of a large amount of data. Concept codes were used to capture the participants' descriptions of their experiences with sleep problems, and the impact on their everyday life. Specific codes related to comprehension, relevance, and acceptability of the items, instructions, response options, recall periods, and ease of use/completion of the measures were also used. All qualitative analyses were performed using ATLAS.ti, version 7.0 or higher (Scientific Software Development $\mathrm{GmbH}$, Berlin, Germany) [22]. Coding dictionaries were developed to aid with the coding. Relevant concepts mentioned in the interviews were tracked to monitor the saturation of concepts. Saturation was defined as the point at which no substantially new information or concepts continued to emerge beyond what had been mentioned in previous interviews [23, 24]. Saturation was documented with the help of saturation grids, where concepts (spontaneously reported or probed) endorsed by participants were listed vertically, and study participant identification numbers representing each individual interview were listed horizontally [14]. The qualitative interviews in phase I were also used to identify thresholds for a meaningful change, and the thresholds for "no or minimal" sleep disturbance in the SD NRS.

\section{Ethics}

Prior to participant recruitment, institutional review board approval (Advarra, Columbia, MD) of the study protocol was obtained. All recruitment procedures complied with current Health Insurance Portability and Accountability Act regulations in the US. Adult participants had to provide written informed consent prior to study procedures. Adolescent participants had to provide informed assent, and their parent or legal guardian had to provide written permission for their child to participate beforehand. All participants also had to consent to being audio recorded during the discussions.

\section{Results \\ Phase I \\ Participants}

In phase I, 20 adult and 10 adolescent participants were enrolled between December 2018 and April 2019 across six clinical sites in the US. The mean age of the adult participants was 33.5 years, and the majority were female $(n=12)$. The mean age of the adolescent participants was 14.1 years, and equal numbers were male and female $(n=$ 5 each) (Table 2). Most participants were White or Asian, and most identified themselves as not Hispanic. According to the site's clinical staff, pruritus was severe for most participants ( $n=13$ adults, $n=7$ adolescents); all other patients were described as having moderate pruritus. The mean \pm standard deviation (SD) Eczema Area and Severity Index (EASI) score was $25.7 \pm 11.5$ (median [range] $=22.5$ [12.0-50.9]) for adults and $26.3 \pm 8.9$ (median [range] = 25.0 [12.2-38.5) for adolescents. The mean \pm SD SCORing Atopic Dermatitis (SCORAD) score was $72.5 \pm 11.0$ (median [range] $=70.8[57.0-97.4])$ for adults and $78.6 \pm 15.6$ (median [range] $=75.0[52.0-95.8]$ ) for adolescents. The EASI and SCORAD scores indicate that all patients had moderate to severe $\mathrm{AD}$ [25].

The mean \pm SD SCORAD VAS for pruritus was $7.7 \pm$ 1.6 (median [range] $=8.1[4.0-9.8]$ ) for adults and $7.6 \pm$ 1.7 (median [range]: 8.0 [5.4-10.0]) for adolescents. The mean \pm SD SCORAD VAS for sleep loss was $7.2 \pm 1.6$ (median [range] $=7.5[4.0-9.7])$ for adults and $6.7 \pm 1.9$ (median [range] $=6.5[4.3-10.0]$ ) for adolescents. Thus, all patients had moderate to very severe pruritus and sleep loss.

\section{Concept elicitation}

Data saturation was assessed following an inductive thematic approach after all interviews had been completed $[23,24]$. Figure 1 shows the saturation grids that summarize the concepts that emerged during the interviews with adults and adolescents, as well as the number of participants who mentioned sleep disturbance concepts spontaneously versus when probed. Saturation was reached after four adult participant interviews and two adolescent participant interviews.

\section{Description of sleep disturbance}

Overall, the most frequent sleep-related issue reported was nighttime awakening (87\% overall: $80 \%$ of adults and $60 \%$ of adolescents), followed by trouble falling asleep (73\% overall: $90 \%$ of adults and $80 \%$ of adolescents), feeling unrested (53\% overall: $60 \%$ of adults and $40 \%$ of adolescents), daytime fatigue or sleepiness (53\% overall: $55 \%$ of adults and $50 \%$ of adolescents), and feeling as though they had not gotten enough sleep (33\% overall: $30 \%$ of adults and $50 \%$ of adolescents) (Fig. 1 and Table 3). Early morning awakening was mentioned 
Table 2 Participant Demographics and Clinical Characteristics

\begin{tabular}{|c|c|c|c|c|}
\hline \multirow[t]{2}{*}{ Characteristic } & \multicolumn{2}{|l|}{ Phase I } & \multicolumn{2}{|l|}{ Phase II } \\
\hline & Adults $(N=20)$ & Adolescents $(N=10)$ & Adults $(N=6)$ & Adolescents $(N=4)$ \\
\hline Age (Years), Mean \pm Standard Deviation & $33.5 \pm 12.8$ & $14.1 \pm 1.9$ & $30.3 \pm 8.7$ & $14.0 \pm 2.2$ \\
\hline \multicolumn{5}{|l|}{ Sex, n (\%) } \\
\hline Male & $8(40)$ & $5(50)$ & $5(83)$ & $2(50)$ \\
\hline Female & $12(60)$ & $5(50)$ & $1(17)$ & $2(50)$ \\
\hline \multicolumn{5}{|l|}{ Ethnicity, n (\%) } \\
\hline Hispanic or Latino & $5(25)$ & $2(20)$ & $1(17)$ & $2(50)$ \\
\hline Not Hispanic or Latino & $15(75)$ & $8(80)$ & $5(83)$ & $2(50)$ \\
\hline \multicolumn{5}{|l|}{ Racial Background, n (\%) } \\
\hline White & $8(40)$ & $4(40)$ & $2(33)$ & $1(25)$ \\
\hline Black or African American & $4(20)$ & $0(0)$ & $2(33)$ & $2(50)$ \\
\hline Asian & $7(35)$ & $5(50)$ & $2(33)$ & $0(0)$ \\
\hline American Indian or Alaska Native & $1(5)$ & $0(0)$ & $0(0)$ & $0(0)$ \\
\hline Other & $0(0)$ & $1(10)$ & $0(0)$ & $1(50)$ \\
\hline \multicolumn{5}{|l|}{ Pruritus $^{\mathrm{a}}, \mathrm{n}(\%)$} \\
\hline Mild & $0(0)$ & $0(0)$ & $0(0)$ & $0(0)$ \\
\hline Moderate & $7(35)$ & $3(30)$ & $2(33)$ & $1(25)$ \\
\hline Severe & $13(65)$ & $7(70)$ & $4(67)$ & $4(75)$ \\
\hline \multicolumn{5}{|l|}{ EASI } \\
\hline Mean \pm Standard Deviation & $25.7 \pm 11.5$ & $26.3 \pm 8.9$ & $33.6(8.4)$ & $31.1(8.0)$ \\
\hline Median [Range] & $22.5[12.0-50.9]$ & $25.0[12.2-38.5]$ & $32.8[23.1-48.1]$ & $32.0[21.8-38.5]$ \\
\hline \multicolumn{5}{|l|}{ SCORAD } \\
\hline Mean \pm Standard Deviation & $72.5 \pm 11.0$ & $78.6 \pm 15.6$ & $71.7(6.7)$ & $82.6(12.3)$ \\
\hline Median [Range] & $70.8[57.0-97.4]$ & $75.0[52.0-95.8]$ & $70.8[63.9-80.4]$ & 82.6 [73.9-91.3] \\
\hline \multicolumn{5}{|l|}{ SCORAD Pruritus VAS } \\
\hline Mean \pm Standard Deviation & $7.7 \pm 1.6$ & $7.6 \pm 1.7$ & $5.9(1.3)$ & $7.9(1.7)$ \\
\hline Median [Range] & $8.1[4.0-9.8]$ & $8.0[5.4-10.0]$ & $6.2[4.0-7.1]$ & $7.9[6.7-9.1]$ \\
\hline \multicolumn{5}{|l|}{ SCORAD Sleep Loss VAS } \\
\hline Mean \pm Standard Deviation & $7.2 \pm 1.6$ & $6.7 \pm 1.9$ & $5.5(1.6)$ & $6.0(0.8)$ \\
\hline Median [Range] & $7.5[4.0-9.7]$ & $6.5[4.3-10.0]$ & $5.2[4.0-8.1]$ & $6.0[5.4-6.5]$ \\
\hline
\end{tabular}

Abbreviations: EASI Eczema Area and Severity Index, SCORAD Scoring Atopic Dermatitis, VAS visual analog scale

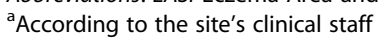

by $40 \%$ of adolescents, but reported by only $5 \%$ of adults.

\section{Frequency of sleep disturbance}

Sleep disturbance was daily for $70 \%$ of adults and $30 \%$ of adolescents, less than daily for $20 \%$ of adults and $70 \%$ of adolescents, and not specified for $10 \%$ of adults. How sleep disturbance varied was obtained from 19 adults and 10 adolescents. For several patients $(32 \%$ of adults and $20 \%$ of adolescents), variation in sleep disturbance was related to whether they were experiencing a flare up. Several others (16\% of adults and $20 \%$ of adolescents) indicated the sleep disturbance depended upon whether or not they had used their medication for AD that day, and one adult participant (5\%) stated that their sleep disturbance depended on the weather. Other participants (26\% of adults and $60 \%$ of adolescents) described the extent of variation in sleep disturbance but did not provide reasons. A few adults (16\%) indicated that the severity of their sleep disturbance did not vary from day to day.

\section{Duration of sleep disturbance}

The duration of total daily sleep varied between participants. One adult (5\%) reported sleeping as little as three to $4 \mathrm{~h}$ per day, while another (5\%) reported sleeping eight to $9 \mathrm{~h}$ per day. One adolescent (10\%) described sleeping as little as $4 \mathrm{~h}$ per day, while another (10\%) 


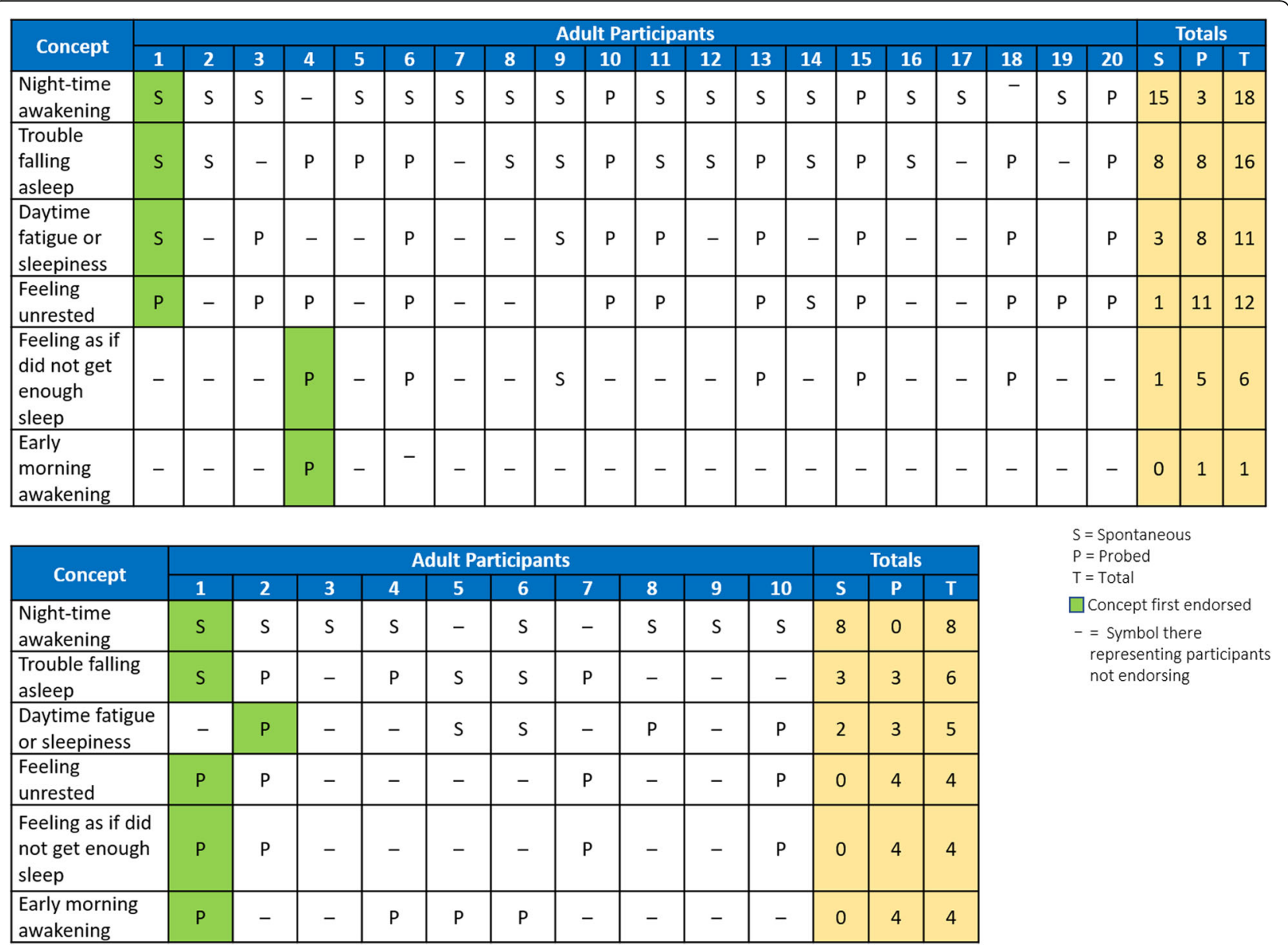

Fig. 1 Saturation Concepts by Individual Adult and Adolescent Participants

slept eight to $10 \mathrm{~h}$. All other participants reported durations of total daily sleep between these extremes.

\section{Description of nighttime awakenings}

The number of awakenings each night varied greatly, although most adult and all adolescent participants reported 1-10 awakenings per night. Two adult participants (10\%) reported waking up 1-2 times per night, and one $(5 \%)$ reported that they did not usually wake up during the night because of being too tired. On the extreme end, another adult (5\%) estimated waking up as many as 10 times per night. A few adolescents (30\%) reported waking up 2-3 times per night; others reported waking up 1-2 times per night (20\%), two times per night (20\%), or five times per night (20\%).

The duration of awakenings also varied. One adult (5\%) reported being awake for as little as a few seconds, while another (5\%) would be awake for an hour. Some adults $(15 \%)$ noted that the amount of time they were awake would vary from a couple minutes to an hour. One adolescent participant (10\%) reported being awake for $10-15 \mathrm{~min}$, while another $(10 \%)$ would be awake for an hour. Another adolescent (10\%) noted that the amount of time awake varied, as it would sometimes be for $15 \mathrm{~min}$ and other times for "hours."

Of 16 adults asked about the ease of falling back asleep after a nighttime awakening, 44\% noted that they could fall asleep easily or quickly and $31 \%$ reported difficulty falling back asleep. Some (31\%) explained that it varied depending on how tired they were, how bad the itch was, or whether they got out of bed to use medication, use lotion, or to shower. Of six adolescents asked this question, most (67\%) reported that they could fall back to sleep easily or quickly.

\section{Causes of sleep disturbance}

Several adults (37\%) and adolescents (43\%) attributed their sleep disturbance solely to itching from AD. The 
Table 3 Phase I Concept Elicitation Results

\begin{tabular}{|c|c|c|}
\hline \multirow[b]{2}{*}{ Concept } & \multicolumn{2}{|c|}{ Frequency } \\
\hline & $\begin{array}{l}\text { Adults } \\
(N= \\
20)\end{array}$ & $\begin{array}{l}\text { Adol } \\
(N=\end{array}$ \\
\hline \multicolumn{3}{|c|}{ Description of Sleep } \\
\hline $\begin{array}{l}\text { Nighttime } \\
\text { awakenings }\end{array}$ & $90 \%$ & $80 \%$ \\
\hline $\begin{array}{l}\text { Trouble falling } \\
\text { asleep }\end{array}$ & $80 \%$ & $60 \%$ \\
\hline $\begin{array}{l}\text { Feeling } \\
\text { unrested }\end{array}$ & $60 \%$ & $40 \%$ \\
\hline $\begin{array}{l}\text { Daytime fatigue } \\
\text { or sleepiness }\end{array}$ & $55 \%$ & $50 \%$ \\
\hline $\begin{array}{l}\text { Did not get } \\
\text { enough sleep }\end{array}$ & $30 \%$ & $40 \%$ \\
\hline $\begin{array}{l}\text { Early-morning } \\
\text { awakening }\end{array}$ & $5 \%$ & $40 \%$ \\
\hline
\end{tabular}

Frequency of Sleep Disturbance

$\begin{array}{lll}\text { Daily } & 70 \% & 30 \% \\ \text { Less than daily } & 20 \% & 70 \%\end{array}$

Did not specify $\quad 10 \% \quad-$

How Sleep Disturbance Varied ${ }^{\text {a }}$

$\begin{array}{lll}\begin{array}{l}\text { Depended on } \\ \text { flare ups }\end{array} & 32 \% & 20 \% \\ \begin{array}{l}\text { Depended on } \\ \text { medication use }\end{array} & 16 \% & 20 \% \\ \begin{array}{l}\text { Depended on } \\ \text { weather }\end{array} & 5 \% & - \\ \begin{array}{l}\text { Varied from day } \\ \text { to day but did }\end{array} & 26 \% & 60 \% \\ \text { not provide } & & \\ \text { reason } & & \\ \begin{array}{l}\text { Depended on } \\ \text { severity or } \\ \text { extent of } \\ \text { itching }\end{array} & & - \\ \begin{array}{l}\text { Sleep did not } \\ \text { vary }\end{array} & 16 \% & - \\ & & \end{array}$

\section{Duration of Sleep per Day}

$\begin{array}{lll}3 \text { to } 4 \mathrm{~h} & 5 \% & 10 \% \\ 4 \text { to } 8 \mathrm{~h} & 90 \% & 80 \% \\ >8 \mathrm{~h} & 5 \% & 10 \%\end{array}$

\section{Awakenings per Night}

$\begin{array}{lll}\text { None } & 5 \% & \\ 1 \text { to } 2 & 10 \% & 40 \% \\ 2 \text { to }<10 & 75 \% & 60 \% \\ \text { Up to } 10 & 5 \% & \\ \text { Unknown } & 5 \% & \end{array}$

Ease of Falling Back Asleep after Nighttime Awakenings ${ }^{b}$

$\begin{array}{lll}\text { Easily } & 44 \% & 67 \% \\ \text { Sometimes } & 31 \% & 17 \%\end{array}$

Illustrative Quotes

Adult participants

Adolescent participants

"I have problems falling asleep, I wake up several

times during the night mainly due to itching ..."

"Sometimes I wake up in the night, but once I get to bed I kind of sit there because my body gets itchy and I have to scratch it a bit before I sleep and then sometimes, I wake up"

"... when it's a bad flare ... it's pretty much nightly ... when I'm relatively healthier and my skin condition is kind of being managed better, then I really don't wake up as much"

"... it depends on how bad and how broad it covers. So, if it's just in one section, it's not as bad as sometimes I have it everywhere and it's really hard for me to fall back asleep because there's no comfortable position, it's itching everywhere"

"... it's definitely in the summer and winter because of the dramatic weather changes"

"... one night I might sleep fine, wake up and like itch my knee or something and fall right back to sleep. Then some nights I might wake up three times and be itching a lot and not really sleep that much"

\footnotetext{
"I probably only get like maybe 4 h of sleep at night, "... around 6-8h" if that. And then with the naps, it's probably I'll only sleep $6 \mathrm{~h}$ a day, seven maybe. But on the weekends, I sleep more obviously because I can take a nap whenever / want."
}

"... sometimes I'll sleep the whole night through. Then sometimes I'll wake up as many as like four time."

"Usually, I usually wake at least two times a day, so it's kind of easy to me now to remember how many times I wake up"
"Depending on how bad I scratch or how itchy it is."

"Sometimes ... I just get up and I regather myself and I fall back to sleep. But sometimes it's hours before I can actually finally go back to sleep" 
Table 3 Phase I Concept Elicitation Results (Continued)

\begin{tabular}{|c|c|c|c|c|}
\hline \multirow[b]{2}{*}{ Concept } & \multicolumn{2}{|c|}{ Frequency } & \multicolumn{2}{|l|}{ Illustrative Quotes } \\
\hline & $\begin{array}{l}\text { Adults } \\
(N= \\
20)\end{array}$ & $\begin{array}{l}\text { Adolescents } \\
(N=10)\end{array}$ & Adult participants & Adolescent participants \\
\hline \multicolumn{5}{|l|}{ easily } \\
\hline Difficulty & $25 \%$ & $17 \%$ & & \\
\hline \multicolumn{3}{|c|}{ Reasons for Sleep Disturbance } & \multirow{3}{*}{$\begin{array}{l}\text { "... the main causes would be eczema and just how } \\
\text { bad the flare up is ... When my skin is really bad, I } \\
\text { get really anxious that I'm going to be scratching all } \\
\text { night..." }\end{array}$} & \multirow{3}{*}{$\begin{array}{l}\text { "[Main cause of sleep disturbance is panic attacks] } \\
\text { correlated to when I'm itchy." }\end{array}$} \\
\hline $\begin{array}{l}\text { Itching from } \\
A D\end{array}$ & $35 \%$ & $30 \%$ & & \\
\hline $\begin{array}{l}\text { Itching from } \\
A D+\text { other } \\
\text { causes }\end{array}$ & $65 \%$ & $70 \%$ & & \\
\hline \multicolumn{3}{|c|}{ Impact on Daily Life } & \multirow{5}{*}{$\begin{array}{l}\text { ".. I feel always drowsy in the morning .... after 2: } \\
00 \text { p.m., yeah, I feel really tiring, so I have to take a } \\
\text { nap for } 30 \text { min at least ..." }\end{array}$} & \multirow{5}{*}{$\begin{array}{l}\text { "I just feel like I'm not performing to my best } \\
\text { because I'm drowsy or not paying full attention } \\
\text { because I'm tired or I'm thinking about something } \\
\text { else just because my head is not fully there." }\end{array}$} \\
\hline $\begin{array}{l}\text { Feeling tired, } \\
\text { fatigued, or } \\
\text { drowsy during } \\
\text { the day }\end{array}$ & $95 \%$ & $50 \%$ & & \\
\hline $\begin{array}{l}\text { Impact on work } \\
\text { or school }\end{array}$ & $30 \%$ & $60 \%$ & & \\
\hline $\begin{array}{l}\text { Affects mood, } \\
\text { increased } \\
\text { irritability }\end{array}$ & $20 \%$ & & & \\
\hline No effect & $15 \%$ & $10 \%$ & & \\
\hline
\end{tabular}

Abbreviation: $A D$ atopic dermatitis

a $N=19$ adults, $N=10$ adolescents

${ }^{\mathrm{b}} N=16$ adults, $N=6$ adolescents

remaining participants attributed the sleep disturbance to a combination of AD-related symptoms (e.g., itching, burning sensations, inflammation, or pain) and other non-AD causes (e.g., consuming caffeinated beverages, asthma, stress, anxiety, or panic attacks).

\section{Impact of sleep disturbance on quality of life}

Several adults (63\%) and adolescents (56\%) mentioned feeling tired, fatigued, or drowsy during the day. Some adult participants (32\%) discussed an impact on work, and most adolescents (67\%) reported an impact on school. Some adults (11\%) reported that sleep disturbance affected their mood, reporting feeling "impatient," "snappy," "irritable," or not "cheery;" other effects included increased stress levels or being lazier during the day (5\% each).

\section{Cognitive interview results: $C S D-A D \odot$}

All adolescents and $90 \%$ of adults had a favorable opinion of the CSD-AD® (Table 4). Typical comments included, "It's actually really easy to fill out and follow," "Simple and easy to understand," "Overall, it's pretty basic, easy for me to answer," and "I think it really helped me see where I was and how I was doing." One adult participant (5\%) commented that the instrument was wordy, though straightforward; another adult (5\%) reported that there were too many questions in the instrument. One more adult (5\%) commented that they had a difficult time accurately quantifying his responses for several items.

Most participants $(80 \%$ of adults and $70 \%$ of adolescents) reported that they could differentiate between the questions in the CSD-AD॰ that had to be completed in the morning and in the evening. Most adults (75\%) and all adolescents stated that the examples in the CSDAD๔ were helpful. A few adults (20\%) commented that one or more instructions for the CSD-AD॰ needed improvement, and one adult (5\%) expressed that the instructions needed additional clarifications. Suggestions for improving the instructions included: specifying the differences between naps and dozing, including adding "about your sleep last night" to the top of the questionnaire, and having examples explained.

\section{Cognitive interview results: SD NRS}

All participants understood the SD NRS question; most found it easy or very easy to understand $(100 \%$ of adults and $90 \%$ of adolescents), and most understood the anchors as intended (95\% of adults and 100\% of adolescents) (Table 4). A few adults (25\%) and adolescents (10\%) provided suggestions for improving the item. Suggestions included replacing the abbreviation "AD" with "atopic dermatitis" (15\% of adults and $10 \%$ of adolescents), adding "eczema" in parenthesis next to "atopic 
Table 4 Phase I Cognitive Debriefing Results for the SD NRS and CSD-AD@

\begin{tabular}{|c|c|c|c|}
\hline Measures & Assessments & Adults $(N=20)$ & Adolescents $(N=10)$ \\
\hline \multirow[t]{6}{*}{ CSD-AD $\odot$} & Overall favorable opinion & $90 \%$ & $100 \%$ \\
\hline & Recommended additional items & $35 \%$ & $10 \%$ \\
\hline & Recommended changes to instructions & $5 \%$ & $0 \%$ \\
\hline & Could differentiate between questions to be completed in the morning vs. evening & $80 \%$ & $70 \%$ \\
\hline & Found examples were helpful & $75 \%$ & $100 \%$ \\
\hline & Recommended rewording & $20 \%$ & $0 \%$ \\
\hline \multirow[t]{16}{*}{ SD NRS } & Able to describe the question properly & $95 \%$ & $100 \%$ \\
\hline & Level of difficulty answering the question & & \\
\hline & Easy or very easy & $85 \%$ & $100 \%$ \\
\hline & Difficult & $10 \%$ & \\
\hline & Not asked & $5 \%$ & \\
\hline & Understood scale and anchors & $90 \%$ & $100 \%$ \\
\hline & Comprehension of 24-h recall period & $100 \%$ & $100 \%$ \\
\hline & Ability to describe recall period ${ }^{a}$ & & \\
\hline & Could describe the 24-h period & $72 \%$ & $100 \%$ \\
\hline & Did not describe but was ok & $17 \%$ & \\
\hline & Too short & $6 \%$ & \\
\hline & No response & $6 \%$ & \\
\hline & Able to recall itch in the past $24 \mathrm{~h}$ or recall period was appropriate & & \\
\hline & Yes & $45 \%$ & $80 \%$ \\
\hline & Provided feedback about recall period & $25 \%$ & \\
\hline & No issue with recall period or did not provide feedback & $30 \%$ & $20 \%$ \\
\hline
\end{tabular}

Abbreviations: $C S D-A D \odot$ Consensus Sleep Diary, atopic dermatitis version, SD NRS sleep disturbance numerical rating scale

${ }^{a} N=18$ adults, $N=10$ adolescents

dermatitis" (10\% of adults), reducing the scale from 1 to 10 to $1-5$ (5\% of adults), adding "getting better" next to the anchor description of "no sleep loss" (5\% of adults), and adding a description under the response option for five on the scale ( $10 \%$ of adolescents).

\section{Meaningful change in SD NRS}

If sufficient time was available during the interviews, participants were queried about what they considered a meaningful change. Of participants $(n=19$ adults and $n=9$ adolescents) asked about the smallest improvement they would be satisfied or content with on the SD NRS, most $(69 \%$ of adults and $88 \%$ of adolescents) indicated a change of one to three points, with a two-point change being the most frequent response (32\% of adults and $44 \%$ of adolescents) (Table 5). Of participants ( $n=17$ adults and $n=10$ adolescents) probed about the levels of improvement that would be meaningful, most (94\% of adults and $90 \%$ of adolescents) indicated that they would consider a change of one or two points in the SD NRS a meaningful change. Of participants $(n=18$ adults and $n=10$ adolescents) asked about what they considered no or minimal sleep disturbance, the most frequent response was score of two (41\% of adults and $40 \%$ of adolescents), followed by one (29\% of adults and $30 \%$ of adolescents) and three (24\% of adults and $10 \%$ of adolescents).

Changes made to the CSD-AD@ following phase I interviews Changes made to the CSD-AD $\odot$ following phase I interviews are summarized in Table 1 . Items $4 a-b$ and $5 a-b$ in the original sleep diary were retained in the revised version (as morning items 4 and 7 ) to estimate the number and duration of awakenings due to AD symptoms and other reasons. The term "final awakening" in these items was replaced by "final time you woke up for the day" because the wording was confusing for some participants. The concept of "itchrelated awakenings" in the items $4 \mathrm{~b}-5 \mathrm{~b}$ was replaced by "awakenings related to AD symptoms" (e.g., itching and burning) to cover all AD symptoms that may cause sleep disturbance. Items $10 \mathrm{a}-\mathrm{b}$ in the original CSD-AD® $\odot$ were separated into four items in the revised $\mathrm{CSD}-\mathrm{AD} \odot$ because they measured two different concepts within the same item (number and duration 
Table 5 Meaningful Change in SD NRS

\begin{tabular}{|c|c|c|c|c|}
\hline \multicolumn{5}{|l|}{ Illustrative Quotes } \\
\hline Assessment & Adults & Adolescents & Adults & Adolescents \\
\hline $\begin{array}{l}\text { Smallest Improvement } \\
\text { with which Participants } \\
\text { Would Be Satisfied or } \\
\text { Content }\end{array}$ & $\begin{array}{l}N= \\
19\end{array}$ & $N=9$ & \multirow[t]{8}{*}{$\ldots$ any improvement is good ... } & \multirow[t]{8}{*}{$\begin{array}{l}\text { I feel like if I was a 5, if I went down that would } \\
\text { be cool, but getting to a } 5 \text { would be-I mean it's } \\
\text { like any improvement would be meaningful. }\end{array}$} \\
\hline 1 point & $11 \%$ & $22 \%$ & & \\
\hline 2 points & $32 \%$ & $44 \%$ & & \\
\hline 3 points & $26 \%$ & $22 \%$ & & \\
\hline 4 points & $16 \%$ & - & & \\
\hline 5 points & $11 \%$ & - & & \\
\hline 6 points & - & $11 \%$ & & \\
\hline 8 points & $5 \%$ & - & & \\
\hline $\begin{array}{l}\text { Level of Improvement } \\
\text { that Would Be } \\
\text { Meaningful }\end{array}$ & $\begin{array}{l}N= \\
17\end{array}$ & $N=10$ & \multirow{4}{*}{$\begin{array}{l}\text { [An improvement of one point]: Maybe I might } \\
\text { sleep a little bit better or maybe I have sleep for } \\
\text { more hours without dealing with a medication. } \\
\text { [An improvement of two points] means I could } \\
\text { go to sleep better and that means I don't have } \\
\text { to wake up in the middle of the night knowing } \\
\text { that I'm scratching myself or that means I can } \\
\text { put makeup on, and it will cover my face. }\end{array}$} & \multirow{4}{*}{$\begin{array}{l}\text { I just feel like the one-point difference is kind of } \\
\text { understandable for just a weekly basis. } \\
\text { [An improvement of three points] I think I would } \\
\text { definitely recognize that, because, I mean, like it's } \\
\text { just a big change from waking up a couple } \\
\text { times to being awake for the duration of the } \\
\text { night. }\end{array}$} \\
\hline 1 point & $76 \%$ & $80 \%$ & & \\
\hline 2 points & $18 \%$ & $10 \%$ & & \\
\hline 3 points & $6 \%$ & $10 \%$ & & \\
\hline $\begin{array}{l}\text { Participants' ratings for } \\
\text { "No or Minimal sleep } \\
\text { disturbance }\end{array}$ & $\begin{array}{l}N= \\
18\end{array}$ & $N=10$ & \multirow{6}{*}{$\begin{array}{l}\text { Well, if my sleep was like a one, I would say } \\
\text { that's still pretty good, that the itch is not there } \\
\text { and if I wake up it's not going to keep me up, it } \\
\text { won't keep me up. }\end{array}$} & \multirow{6}{*}{$\begin{array}{l}\text { I'm sleeping at a one or a two, and just being to } \\
\text { sleep well because that's like a basic thing that } \\
\text { everybody else can do. It's just something that I } \\
\text { wish I had the privilege to be able to just sleep } \\
\text { through the night without waking up from my } \\
\text { neck hurts or thinking about how my skin is } \\
\text { bothering. I kind of just wish I could sleep like a } \\
\text { normal person. }\end{array}$} \\
\hline 0 & $11 \%$ & $10 \%$ & & \\
\hline 1 & $29 \%$ & $30 \%$ & & \\
\hline 2 & $41 \%$ & $40 \%$ & & \\
\hline 3 & $24 \%$ & $10 \%$ & & \\
\hline 4 & - & $10 \%$ & & \\
\hline
\end{tabular}

Abbreviation: $S D$ NRS sleep disturbance numerical rating scale

of naps or dozing). Although participants understood the concepts as intended (i.e., that dozing lasted seconds or a few minutes, whereas naps lasted many minutes to over an hour), a few $(n=3)$ had difficulty in providing a combined answer, and one participant suggested separating the two concepts. In the revised CSD-AD○, these items were separated into four different items, including different items for dozing and naps, but the wording remained unchanged. An item asking participants what time they get out of bed for the day that is included in the CSD [11] but not in the original version of the CSD-AD॰ was added to allow key sleep metrics to be derived, such as total time spent in bed and sleep efficiency.

\section{Changes made to the SD NRS following phase I interviews}

Based on the recommendations made during the cognitive interviews during phase I, the abbreviation "AD" in the SD NRS was replaced with "atopic dermatitis" or "your skin disease," and the anchor "I cannot sleep at all" was changed to "I did not sleep at all" (Table 1).

\section{Phase II}

\section{Participants}

A convenience sample of six adult and four adolescent participants from phase I were invited to participate in phase II, which examined the content validity of the revised $C S D-A D \odot$. The mean age was $30.3 \pm 8.7$ years for the adult participants and $14.0 \pm 2.2$ years for the adolescent participants (Table 2). Participants were mostly White ( $n=2$ adults and $n=1$ adolescent), Asian ( $n=2$ adults and $n=2$ adolescents), or Black or African American ( $n=2$ adults). Most adult participants were not Hispanic or Latino $(n=5)$, but half of adolescent participants $(n=2)$ reported being Hispanic or Latino. According to the site's clinical staff, most participants had severe pruritus ( $n=4$ adults and $n=3$ adolescents). The mean EASI was $33.6 \pm 8.4$ for adults and $31.1 \pm 8.0$ for adolescents, and the mean SCORAD was 7.0 \pm 6.7 for adults and $82.6 \pm 12.3$ for adolescents. The mean SCORAD VAS for pruritus was $5.9 \pm 1.3$ for adults and $7.9 \pm 1.7$ for adolescents, and the mean SCORAD VAS for sleep loss was $5.5 \pm 1.6$ for adults and $6.0 \pm 0.8$ for adolescents. 


\section{Cognitive interview results}

Overall, the majority of participants understood the items of the revised CSD-AD@ as intended (Table 6). Participants also indicated being able to accurately recall and select an answer for each item. Only two items (morning items 5 and 7) appeared difficult to understand and recall accurately. Morning item 5, which asked how long awakenings due to $\mathrm{AD}$ lasted, was found by one participant to be "a little bit confusing" because of not clearly understanding that the total number of minutes was to include time awake not only directly due to itching but also as an indirect consequence of itching. In addition, one participant did not clearly understand the recall period of morning item 7, which asked how long awakenings due to other reasons lasted, asking, "Are you talking about last night specifically or sometime during the month or?" Morning items 5 and 7 were also found to be difficult to recall accurately by one participant each. In the case of morning item 5 , the participant stated that the total time “... might not be too accurate because I didn't check my phone those times." For morning item 7, the participant found the instructions clear, but stated, "I myself can't really be accurate toward it."

\section{Discussion}

This qualitative study supports the importance and relevance of sleep disturbance in adolescents and adults with moderate-to-severe $\mathrm{AD}$ and pruritis. We found that $\mathrm{AD}$ associated sleep disturbance is a multidimensional concept, and that nighttime awakenings, trouble falling asleep, and feeling unrested are experienced by most participants. Other common issues included daytime fatigue or sleepiness, a feeling of not having had enough sleep, and an early-morning awakening. The current study also revealed that the degree of sleep disturbance varies substantially from day to day in patients with $A D$ due to varying extents of itching and flares, medication use, and changes in the weather.

Our findings agree with a recent systematic literature review, which reported that adults with $\mathrm{AD}$ frequently experience sleep disturbance (prevalence of 33\% to 87.1\%), difficulty falling asleep, frequent/extended awakenings, and shorter sleep durations, which result in daytime sleepiness, fatigue, and reduced functioning [3]. The current results also agree with studies showing that a sleep disturbance is one of the most important components of the burden of chronic itch [26], that pruritus

Table 6 Phase II Assessment of the Revised CSD-ADC

\begin{tabular}{|c|c|c|c|c|c|}
\hline \multirow[t]{2}{*}{ Items } & \multirow{2}{*}{$\begin{array}{l}\text { Item was } \\
\text { Clear and } \\
\text { Easy to } \\
\text { Understand }\end{array}$} & \multicolumn{3}{|c|}{ Ease of Recalling the Experience } & \multirow{2}{*}{$\begin{array}{l}\text { Instructions } \\
\text { were Clear } \\
\text { and Easy to } \\
\text { Understand }\end{array}$} \\
\hline & & Easy & Somewhat Easy & Difficult & \\
\hline \multicolumn{6}{|l|}{ CSD-AD $\odot$ Morning Items } \\
\hline Item 1. What time did you get into bed? & $8 / 8(100)$ & 9/9 (100) & $0 / 9(0)$ & $0 / 9(0)$ & $5 / 5(100)$ \\
\hline Item 2. What time did you try to go to sleep? & $10 / 10(100)$ & 8/9 (89) & $1 / 9(11)$ & $0 / 9(0)$ & $7 / 7(100)$ \\
\hline Item 3. How long did it take you to fall asleep? & 9/9 (100) & $6 / 10(60)$ & $4 / 10(40)$ & 0/8 (0) & $7 / 7(100)$ \\
\hline $\begin{array}{l}\text { Item } 4 \text {. How many times did you wake up due to the symptoms } \\
\text { of atopic dermatitis (for example itching, burning), not counting } \\
\text { the final time you woke up for the day? }\end{array}$ & $8 / 8(100)$ & $7 / 10(70)$ & $3 / 10(30)$ & 0/10 (0) & $7 / 7(100)$ \\
\hline $\begin{array}{l}\text { Item } 5 . \text { In total, how long did the awakenings related to the } \\
\text { symptoms of atopic dermatitis (for example itching, burning) last? }\end{array}$ & $8 / 8(100)$ & $5 / 9(56)$ & 3/9 (33) & $1 / 9(11)$ & 6/7 (86) \\
\hline $\begin{array}{l}\text { Item 6. How many times did you wake up, for other things (for } \\
\text { example to drink water, to go to the bathroom), not counting } \\
\text { the final time you woke up for the day? }\end{array}$ & $8 / 8(100)$ & 6/7 (86) & $1 / 7(14)$ & $0 / 10(0)$ & $7 / 7(100)$ \\
\hline $\begin{array}{l}\text { Item 7. In total, how long did these awakenings related to other } \\
\text { things (for example to drink water, to go to the bathroom) last? }\end{array}$ & $7 / 8(88)$ & $6 / 8(75)$ & $1 / 8(13)$ & $1 / 8(13)$ & $6 / 6(100)$ \\
\hline Item 8. What time did you wake up for the day? & $8 / 8(100)$ & 9/9 (100) & $0 / 9(0)$ & $0 / 9(0)$ & $7 / 7(100)$ \\
\hline Item 9. What time did you get out of bed for the day? & $8 / 8(100)$ & $10 / 10(100)$ & $0 / 10(0)$ & $0 / 10(0)$ & $7 / 7(100)$ \\
\hline Item 10. How would you rate the quality of your sleep? & $8 / 8(100)$ & 9/9 (100) & $0 / 9(0)$ & $0 / 9(0)$ & $7 / 7(100)$ \\
\hline $\begin{array}{l}\text { Item 11. How rested or refreshed did you feel when you woke } \\
\text { up for the day? }\end{array}$ & $8 / 8(100)$ & $8 / 8(100)$ & $0 / 8(0)$ & 0/8 (0) & $7 / 7(100)$ \\
\hline \multicolumn{6}{|l|}{ CSD-AD $\odot$ Evening Items } \\
\hline Item 1. How many times did you nap? & $8 / 8(100)$ & $8 / 8(100)$ & $0 / 8(0)$ & $0 / 6(0)$ & $7 / 7(100)$ \\
\hline Item 2. In total, how long did you nap? & $8 / 8(100)$ & $6 / 6(100)$ & $0 / 6(0)$ & $0 / 6(0)$ & $6 / 6(100)$ \\
\hline Item 3. How many times did you doze off? & $7 / 7(100)$ & $7 / 8(86)$ & $1 / 8(13)$ & 0/8 (0) & 7/7 (100) \\
\hline Item 4. In total, how long did you doze off? & 7/7 (100) & $4 / 5(80)$ & $1 / 5(20)$ & $0 / 5(0)$ & 7/7 (100) \\
\hline
\end{tabular}


and scratching are a principal cause of sleep disturbance in patients with $\mathrm{AD}$ [27], and that the degree of sleep disturbance and sleep loss corresponds with the severity of $\mathrm{AD}[4,5]$.

To measure daily sleep disturbance in patients with $\mathrm{AD}$, we adapted the Consensus Sleep Diary, a standardized, prospective tool for tracking nightly subjective sleep [11]. The resulting CSD-AD@ effectively captured the different dimensions of the sleep disturbance concept, and the items included in the revised version were understood as intended. Participants were able to accurately recall and select an answer to each question, and they indicated that the concepts included in the CSD$\mathrm{AD} \odot$ were important and relevant. Using the CSD-AD®, we found that one-third of participants attributed the sleep disturbance solely to their itching, while the remaining participants attributed the sleep disturbance to both AD-related symptoms (e.g. itching, burning sensations, inflammation, or pain) and other non-AD causes (e.g. consuming caffeinated beverages, asthma, stress, anxiety, or panic attacks). A critical finding was that most participants were able to distinguish between night-time awakenings due to $\mathrm{AD}$-symptoms and nighttime awakening due to other causes. They also indicated that they could recall the number and duration of their awakenings.

The CSD-AD@ was revised based on the results of the interviews during the first phase of the study. Changes to the $\mathrm{CSD}-\mathrm{AD} \odot$ included adding one item, separating some items into multiple, changing the item wording, changing the order of items, and modifying the instructions. One important issue was that some items measured two distinct concepts within the same item (e.g., number and duration of naps or dozing), and used a different timeframe, (daytime) requiring an additional administration of the questionnaire in the evening. Based on participant feedback, different items were created for dozing and naps. To ensure that the changes made to the $\mathrm{CSD}-\mathrm{AD} \odot$ were endorsed and understood by the target population, during phase II, additional interviews were conducted with a convenience sample of six adult and four adolescent participants from phase I. The revised CSD-AD॰ was endorsed and understood by the participants, and no further changes were needed. Only two items appeared difficult to understand and recall accurately. This is unlikely to be problematic in the context of a clinical trial, where the participants will be trained on the use of the diary and where they will be instructed to report their nighttime awakenings within an hour of getting out of bed. Because the Consensus Sleep Diary was originally developed for insomnia, the scoring and psychometric properties of the CSD-AD and the additional sleep parameters derived from the new items remain to be assessed in $\mathrm{AD}$.
To support the potential use of the SD NRS as an endpoint in $\mathrm{AD}$ clinical trials for evaluating the meaningful treatment effects on this population, we also investigated thresholds for meaningful change. Although data on meaningful change are often collected using quantitative approaches (especially anchor- and distribution-based methods) [28], we evaluated thresholds using a qualitative approach to reflect the direct patient perspective, which is increasingly valued by regulators [29]. Most participants considered a one-point improvement to be a meaningful change, although they most frequently reported that they would be satisfied or content with a two-point change. This information will be used to inform the responder definition threshold estimates assessed quantitatively using anchor- and distributionbased methods.

Additional research is in progress to generate quantitative evidence on the psychometric measurement properties of the CSD-AD॰ and SD NRS, as well as to derive responder definition threshold estimates. In addition, following International Society for Pharmacoeconomics and Outcomes Research principles [30,31], we are conducting linguistic validations of the translations, migrating the questionnaires to electronic devices, and conducting usability testing of the selected devices and cognitive debriefings to assess device functionality, instrument comprehension, and ease of use in the intended population.

This study benefitted from the inclusion of a relatively large group of patients with $\mathrm{AD}$ who were recruited from both sexes, geographically diverse regions of the US, and different ethnic and racial backgrounds. A potential limitation of this study could be that although the CSD is intended for insomnia, the CSD-AD॰ was revised based on interviews of patients that were not specifically diagnosed with insomnia. Thus, the findings from the $\mathrm{CSD}-\mathrm{AD} \odot$ and related cognitive interviews may be limited to patients with undetermined sleep disturbance. Another potential limitation could be that because the objective of the study was to establish content validity, the CSD-AD@ and SD NRS were completed at the time of the cognitive interviews and not immediately after sleep disturbance (as intended for both the CSD-AD॰ and the SD NRS) or in the evening (as intended for the CSD-AD $\odot$ ). This may have resulted in memory bias or an increased difficulty in answering some items. However, it should not have affected the overall conclusions about content validity of the CSD-AD@ or SD NRS.

To evaluate the effect of AD treatments in clinical settings and capture the multidimensionality of the $\mathrm{AD}$ related sleep disturbance concepts, we recommend using the SD NRS in conjunction with the CSD-AD@. Nightly self-reported sleep in a diary is regarded as the "gold 
standard" for the subjective assessment of sleep and tracking of sleep disorders [11]. A potential disadvantage of the CSD-AD॰ and SD NRS is that they require daily reporting, which could result in a heavy administrative burden or the possibility of missing an assessment. To limit this and possible memory bias due to delayed reporting, for clinical trials, the CSD-AD॰ and SD NRS will be collected using an electronic device with a reminder or alarm function.

\section{Conclusions}

This qualitative study showed that sleep disturbance is a relevant, multi-dimensional concept that is important, is significant to patients with $\mathrm{AD}$, and can be assessed using self-reported measures. The study further showed that the CSD-AD॰ and SD NRS yield relevant and meaningful data about AD-related sleep disturbance, and it supports the use of these instruments in clinical trials evaluating the effects of treatments in this population, although their psychometric measurement properties and responder thresholds remain to be established.

\section{Supplementary Information}

Supplementary information accompanies this paper at https://doi.org/10. 1186/s41687-020-00265-y.

\section{Additional file 1}

\section{Abbreviations}

AD: Atopic dermatitis; CSD-AD: Consensus Sleep Diary, atopic dermatitis version; EASI: Eczema Area and Severity Index; PRO: Patient-reported outcome; SCORAD: SCORing Atopic Dermatitis; SD NRS: Sleep disturbance numerical rating scale; VAS: Visual analogue scale

\section{Acknowledgements}

The authors thank: Phillip Leventhal, PhD (Evidera) for medical writing; Fatoumata Fofana and Danielle Rodriguez for reviewing the article; Andrea Schutz for analyzing the results and reporting; and the interviewers and coders for conducting the interviews and coding the transcripts. Medical writing was paid for by Galderma.

\section{Authors' contributions}

CDB designed the study, and was involved in the analysis, results interpretation, and reporting. RM was involved in the development of study documents, data collection, analyses and reporting. MV was involved in the study design and results interpretation. AK and CEC were involved in the results interpretation, and reviewed the manuscript. And JP was involved in the study design, results interpretation, and reporting. The author(s) read and approved the final manuscript.

\section{Funding}

The study was funded by Galderma.

\section{Availability of data and materials}

The data that support the findings of this study are available from Galderma, but restrictions apply to the availability of these data and, so, are not publicly available. Data are however available from the authors upon reasonable request and with permission of Galderma.

\section{Ethics approval and consent to participate}

Adult participants had to provide written informed consent prior to study procedures. Adolescent participants had to provide informed assent, and their parent or legal guardian had to provide written permission for their child to participate beforehand. All participants also had to consent to being audio recorded during the discussions. All recruitment procedures complied with current Health Insurance Portability and Accountability Act regulations in the US. Evidera obtained institutional review board approval of the study protocol in the US prior to participant recruitment.

\section{Consent for publication}

Not applicable.

\section{Competing interests}

AK reports research funding from the National Institutes of Health (NIH), Patient-Centered Outcomes Research Institute (PCORI), Janssen, Jazz, Axsome and Reveal Biosensors, as well as consulting fees from Eisai, Ferring, Galderma, Harmony Biosciences, Idorsia, Jazz, Janssen, Takeda, Merck, Neurocrine, Pernix, Sage, and Evecxia. CDB, RM, and MV are employees of Evidera, a firm contracted by Galderma to conduct the research. JP is an employee of Galderma

\section{Author details}

${ }^{1}$ Evidera, The Ark, 201 Talgarth Road Hammersmith, London W6 8BJ, UK. Evidera, 7101 Wisconsin Avenue, Suite 1400, Bethesda, MA 20814, USA ${ }^{3}$ Ryerson University, 350 Victoria Street, Toronto, ON M5B 2K3, Canada. ${ }^{4}$ University of California, San Francisco, Weill Institute for Neurosciences, 401 Parnassus Avenue, San Francisco, CA 94143-0984, USA. ${ }^{5}$ Galderma, World Trade Center, Avenue Gratta-Paille 2, 1018 Lausanne, Switzerland.

Received: 5 April 2020 Accepted: 3 November 2020 Published online: 23 November 2020

\section{References}

1. Kapur, S., Watson, W., \& Carr, S. (2018). Atopic dermatitis. Allergy, Asthma and Clinical Immunology, 14(Suppl 2), 52.

2. Roesner, L. M., \& Werfel, T. (2019). Autoimmunity (or not) in atopic dermatitis. Frontiers in Immunology, 10, 2128.

3. Jeon, C., Yan, D., Nakamura, M., et al. (2017). Frequency and management of sleep disturbance in adults with atopic dermatitis: A systematic review. Dermatology and Therapy (Heidelberg), 7(3), 349-364.

4. Bender, B. G., Ballard, R., Canono, B., Murphy, J. R., \& Leung, D. Y. (2008). Disease severity, scratching, and sleep quality in patients with atopic dermatitis. Journal of the American Academy of Dermatology, 58(3), 415-420.

5. Li, J. C., Fishbein, A., Singam, V., et al. (2018). Sleep disturbance and sleeprelated impairment in adults with atopic dermatitis: A cross-sectional study. Dermatitis, 29(5), 270-277.

6. Yu, S. H., Attarian, H., Zee, P., \& Silverberg, J. I. (2016). Burden of sleep and fatigue in US adults with atopic dermatitis. Dermatitis, 27(2), 50-58.

7. Silverberg, J. I., Garg, N. K., Paller, A. S., Fishbein, A. B., \& Zee, P. C. (2015) Sleep disturbances in adults with eczema are associated with impaired overall health: A US population-based study. The Journal of Investigative Dermatology, 135(1), 56-66.

8. Barrett, A., Hahn-Pedersen, J., Kragh, N., Evans, E., \& Gnanasakthy, A. (2019). Patient-reported outcome measures in atopic dermatitis and chronic hand eczema in adults. Patient, 12(5), 445-459.

9. Chang, Y. S., Lin, M. H., Lee, J. H., et al. (2016). Melatonin supplementation for children with atopic dermatitis and sleep disturbance: A randomized clinical trial. JAMA Pediatrics, 170(1), 35-42.

10. Hon, K. L., Lam, M. C., Leung, T. F., Chow, C. M., Wong, E., \& Leung, A. K. (2007). Assessing itch in children with atopic dermatitis treated with tacrolimus: Objective versus subjective assessment. Advances in Therapy, 24(1), 23-28.

11. Carney, C. E., Buysse, D. J., Ancoli-Israel, S., et al. (2012). The consensus sleep diary: Standardizing prospective sleep self-monitoring. Sleep, 35(2), 287-302.

12. Ji, X., \& Liu, J. (2016). Subjective sleep measures for adolescents: A systematic review. Child: Care, Health and Development, 42(6), 825-839.

13. Lewandowski, A. S., Toliver-Sokol, M., \& Palermo, T. M. (2011). Evidencebased review of subjective pediatric sleep measures. Journal of Pediatric Psychology, 36(7), 780-793.

14. Patrick, D. L., Burke, L. B., Gwaltney, C. J., et al. (2011). Content validity-establishing and reporting the evidence in newly developed patientreported outcomes (PRO) instruments for medical product evaluation: ISPOR PRO good research practices task force report: Part 1--eliciting concepts for a new PRO instrument. Value in Health, 14(8), 967-977. 
15. Patrick, D. L., Burke, L. B., Powers, J. H., et al. (2007). Patient-reported outcomes to support medical product labeling claims: FDA perspective. Value in Health, 10(Suppl 2), S125-S137.

16. US Food and Drug Administration (2009). Guidance for industry patientreported outcome measures: Use in medical product development to support labeling claims. Rockville: US FDA.

17. Patrick, D. L., Burke, L. B., Gwaltney, C. J., et al. (2011). Content validityestablishing and reporting the evidence in newly developed patientreported outcomes (PRO) instruments for medical product evaluation: ISPOR PRO good research practices task force report: Part 2--assessing respondent understanding. Value in Health, 14(8), 978-988.

18. European Task Force on Atopic Dermatitis (1993). Severity scoring of atopic dermatitis: the SCORAD index. Consensus report of the European task force on atopic dermatitis. Dermatology., 186(1), 23-31.

19. Hanifin, J. M., Thurston, M., Omoto, M., Cherill, R., Tofte, S. J., \& Graeber, M. (2001). The eczema area and severity index (EASI): Assessment of reliability in atopic dermatitis. EASI Evaluator Group. Experimental Dermatology, 10(1), $11-18$.

20. Leidy, N. K., \& Vernon, M. (2008). Perspectives on patient-reported outcomes : Content validity and qualitative research in a changing clinical trial environment. Pharmacoeconomics, 26(5), 363-370.

21. SAS Institute SAS version 9.4. Cary: SAS Institute.

22. ATLAS.ti Scientific Software Development GmbH. ATLAS.ti version 7.0 or higher. Berlin, Germany: ATLAS.ti Scientific Software Development GmbH.

23. Saunders, B., Sim, J., Kingstone, T., et al. (2018). Saturation in qualitative research: Exploring its conceptualization and operationalization. Quality and Quantity, 52(4), 1893-1907.

24. Faulkner, S. L., \& Trotter, S. P. (2017). Data saturation. In The International Encyclopedia of Communication Research Methods, (pp. 1-2).

25. Chopra, R., Vakharia, P. P., Sacotte, R., et al. (2017). Severity strata for eczema area and severity index (EASI), modified EASI, scoring atopic dermatitis (SCORAD), objective SCORAD, atopic dermatitis severity index and body surface area in adolescents and adults with atopic dermatitis. The British Journal of Dermatology, 177(5), 1316-1321.

26. Silverberg, J. I., Kantor, R. W., Dalal, P., et al. (2018). A comprehensive conceptual model of the experience of chronic itch in adults. American Journal of Clinical Dermatology, 19(5), 759-769.

27. Huet, F., Faffa, M. S., Poizeau, F., Merhand, S., Misery, L., \& Brenaut, E. (2019). Characteristics of pruritus in relation to self-assessed severity of atopic dermatitis. Acta Dermato-Venereologica, 99(3), 279-283.

28. Cappelleri, J. C., \& Bushmakin, A. G. (2014). Interpretation of patient-reported outcomes. Statistical Methods in Medical Research, 23(5), 460-483.

29. Mercieca-Bebber, R., King, M. T., Calvert, M. J., Stockler, M. R., \& Friedlander, M. (2018). The importance of patient-reported outcomes in clinical trials and strategies for future optimization. Patient Related Outcome Measures, 9, 353-367.

30. Coons, S. J., Gwaltney, C. J., Hays, R. D., et al. (2009). Recommendations on evidence needed to support measurement equivalence between electronic and paper-based patient-reported outcome (PRO) measures: ISPOR ePRO good research practices task force report. Value in Health, 12(4), 419-429.

31. Wild, D., Grove, A., Martin, M., et al. (2005). Principles of good practice for the translation and cultural adaptation process for patient-reported outcomes (PRO) measures: Report of the ISPOR task force for translation and cultural adaptation. Value in Health, 8(2), 94-104.

\section{Publisher's Note}

Springer Nature remains neutral with regard to jurisdictional claims in published maps and institutional affiliations.

\section{Submit your manuscript to a SpringerOpen ${ }^{\circ}$ journal and benefit from:}

- Convenient online submission

- Rigorous peer review

- Open access: articles freely available online

High visibility within the field

- Retaining the copyright to your article

Submit your next manuscript at $\boldsymbol{\nabla}$ springeropen.com 